\title{
APLIKASI SISTEM PENGELOLAAN PANTI SOSIAL BINA REMAJA "BUDI SATRIA" BANJARBARU BERBASIS WEB
}

\author{
Ibrahim ${ }^{1}$ \\ ${ }^{1}$ Fakultas Teknologi Informasi, Universitas Islam Kalimantan Muhammad Arsyad Al Banjari Banjarmasin \\ Email : Terrasin06@gmail.com
}

\begin{abstract}
Abstrack
Aplikasi pengelolaan dinas sosial yang ada pada Panti Sosial Bina Remaja (PSBR) "Budi Satria" Banjarbaru Provinsi Kalimantan Selatan ini masih menggunakan sistem yang manual. Hal ini menimbulkan beberapa kendala yang cukup merepotkan, terutama pada ketidakvalidan dan ketidakcocokan data. Sering pula terjadi kendala pada saat pencarian informasi tentang data-data siswa, data-data setiap pengajar, maupun pada saat ingin menginput suatu data.

Demikian pula halnya dengan penyediaan data, misalnya data siswa jurusan, data tempat magang siswa dan siswa magang, data siswa jurusan, siswa asrama, dan data penyalur ataupun pengajar. Maka pada penelitian/skripsi ini dibuatlah aplikasi pengelolaan berbasis web yang dapat mempermudah petugas dalam menginput data secara cepat, tepat dan efisien.

Aplikasi yang dibangun ini, dibuat dengan menggunakan tools seperti sublime, PHPMyAdmin, MySQL sebagai database dengan bahasa pemprograman HTML dan PHP, dan dirancang dengan alur serta rancangan antar muka yang sederhana menggunakan metode perancangan meliputi, perancangan DFD, Flowchart, struktur tabel database dan beberapa perancangan diagramdiagram lainnya yang menjelaskan alur berjalannya aplikasi pengelolaan ini, sehingga dapat dengan mudah digunakan di lingkungan panti sosial.
\end{abstract}

Kata Kunci : HTML, MySQL, Web Aplikasi, Pengelolaan PSBR “Budi Satria” dan PHP

\section{PENDAHULUAN}

Panti Sosial Bina Remaja (PSBR) "Budi Satria" Provinsi Kalimantan Selatan Kota Banjarbaru merupakan Instansi pemerintah yang mempunyai tugas memberikan pembinaan kesejahteraan sosial kepada anak terlantar putus sekolah yang berada di setiap kabupaten di kalimantan selatan.

Pengelolaan yang ada pada panti sosial bina remaja ini berisi informasi tentang data-data seperti data siswa, siswa perangkatan, siswa jurusan, siswa asrama, pembagian siswa magang, data pengajar, akademik penilaian nilai bimbingan dan nilai keterampilan, penyalur panti, dan pembuatan surat izin keluar untuk siswa, namun masih menggunakan sistem manual dalam pemprosesan data tersebut. Hal tersebut mempunyai kelemahan yaitu antara lain banyak data atau laporan yang tidak di arsipkan dengan baik, pencarian data memakan waktu karena banyak nya data siswa perangkatan dan keterbatasan tempat untuk menampung file-file yang ada. Dalam peningkatan pengolahan data merupakan hal yang sangat perlu dilakukan demi kelancaran sistem akademik yang ada di panti sosial pembenahan ini meliputi komponen-komponen panti sosial itu sendiri Berdasarkan pengamatan pada PSBR "Budi Satria" Banjarbaru sendiri belum mempunyai sebuah media yang dapat memproses data-data berbasis komputerisasi, maka dari penulis akan mencoba melakukan penelitian tentang pembuatan aplikasi pengelolaan pada Panti Sosial Bina Remaja "Budi Satria" Banjarbaru agar hal ini bisa dijadikan sebagai bentuk perbaikan ataupun membantu dalam pengelolaan data 
akademik serta mempermudah petugas atau staf dan pencetakan nilai dan laporan. Untuk mengatasi permasalahan tersebut diperlukan suatu solusi yaitu menggunakan aplikasi pengelolaan yang terkomputerisasi berbasis web agar pengarsipan dan pendataan lebih akurat dan efisien

$$
\text { Sejumlah penelitian telah }
$$
dilakukan dalam membangun sebuah sistem informasi pengelolaan, diantaranya penelitian tentang "Sistem Informasi Terpadu Sekolah Dasar Berbasis Web Dengan Php dan MySQL" oleh Maria Heti Estri Sulistiyorini (2011), ada beberapa masalah atau kendala dari sistem yang dibuat dimana belum tersistemnya alur data dari form dan tampilan juga masih kurang userfriendly (menggunakan sesuatu dengan mudah dan nyaman).

Salah satu perangkat lunak pengembangan aplikasi yang di ajukan oleh penulis ialah Berbasis Web menggunakan PHP dan MySQL, Menangani pengolahan data siswa, pengajar dan pegawai sangatlah efektif dibandingkan dengan sistem pemprosesan manual, kerana PHP MySQL merupakan software yang bisa digunakan untuk membuat program yang dapat membantu system akademik yang ada di PSBR. Didukung dengan perangkat lunak dan konfigurasi perangkat keras yang tepat, panti sosial dapat membangun sistem informasi manajemen yang handal dan berpengaruh secara signifikan terhadap kinerja pada panti sosial secara keseluruhan. Keadaan ini mendorong suatu usaha untuk merancang suatu sistem informasi pengelolaan pada PSBR "Budi Satria” Banjarbaru.

\section{TINJAUAN PUSTAKA}

\section{A. Konsep Dasar Sistem}

Sistem ialah berasal dari bahasa yunani "sytema" yang artinya kesatuan. Suatu sistem ini terdiri dari elemen-elemen yang paling berinteraksi untuk mencapai tujuan tertentu.

"Sistem adalah suatu jaringan kerja yang terdiri dari prosedur-prosedur yang saling berhubungan, berkumpul bersama- sama untuk melakukan suatu kegiatan atau menyelesaikan suatu sasaran tertentu" (Ponco W.Sigit, 1999:1)

Suatu sistem yang ingin mencapai tujuannya tentu memperlukan proses dengan beberapa tipe proses dari proses secara konsep, proses secara fisik, proses secara prosedur, proses secara sosial dan proses yang mendukung dalam mencapai tujuan tersebut.

Jogiyanto (2005:1), mendifinisikan sistem adalah "sistem dapat terdiri dari sistem-sistem bafian (subsistem) yang saling berintraksi, sebagai akibat adanya input yang diproses menjadi output/informasi, misalnya sebuah komputer terdiri dari beberapa komponen".

Sistem merupakan bagian yang saling berkaitan erat dan membentuk suatu kesatuan yang saling berinteraksi antara bagian satu dengan bagian lainnya untuk mencapai suatu tujuan, artinya apabila salah satu bagian dari sistem tidak ada maka sistem tersebut tidak akan berfungsi sebagai mana mestinya yang diharapkan.

"Jaringan kerja dari prosedur-prosedur yang saling berhubungan, berkumpul bersama-sama untuk melakukan suatu kegiatan atau menyelesaikan suatu sasaran tertentu".

Adapun definisi Sistem adalah kumpulan dari komponen atau elemen yang berinteraksi untuk mencapai tujuan tertentu. "Definisi sistem itu sendiri yang menekankan pada komponen atau elemen memiliki pengertian yang lebih luas dari pada penekanan pada prosedur karena pengertian tersebut lebih diterima dikarenakan suatu sistem terdiri beberapa subsistem-subsistem" (Jogiyanto, $2005: 2$ ). Jadi dapat disimpulkan bahwa suatu sistem terdapat beberapa elemen-elemen yang bertujuan sama dan ada beberapa yang lebih unggul sebagai penyerap dan pencatat data yang tidak dapat berdiri sendiri saling berinteraksi atau berhubungan dengan yang lain yang membentuk suatu kesatuan yang utuh. 


\section{B. Sistem Informasi}

Sistem informasi adalah suatu sistem di dalam suatu organisasi yang dipertemukan kebutuhan pengolahan transaksi harian yang mendukung fungsi operasi organisasi yang bersifat manajerial dengan kegiatan strategi dari organisasi untuk menyediakan kepada pihak luar tertentu dengan laporanlaporan yang diperlukan (Steven Alter, 2002:42)

"Andi (2005:9) mengatakan bahwa Sistem informasi adalah suatu komponen yang saling berhubungan yang mengumpulkan (mendapatkan-kembali), memproses, menyimpan, dan mendristribusikan informasi untuk mendukung pengambilan keputusan dan kendali dalam suatu organisasi"

Menurut (Abdul Kadir, 2003:10) Sistem informasi merupakan sejumlah komponen (manusia, komputer, teknologi informasi dan prosedur kerja), ada suatu yang diproses data menjadi informasi dan dimasudkan untuk mencapai sasaran dan tujuan.

\section{Konsep Dasar Sistem Informasi \\ Manajement}

Tujuan dari sebuah sistem informasi manajemen adalah untuk mengintegrasikan semua sistem informasi dalam organisasi dan untuk memonitor kegiatan-kegiatan dalam sekolah/perusahaan agar lebih mudah untuk mengetahui apakah kegiatan terus berjalan sebagaimana mestinya dan telah berimbang.

Sebuah sistem informasi manajemen berhubungan dengan organisasi dan manusia sebagai pengelolanya, oleh sebab itu pemahaman utuh terdapat sistem informasi keorganisasian berdasarkan komputer harus juga termasuk memahami konsep berhubungan dengan informasi, pemakai informasi, serta nilai sebuah informasi.

Menurut (Bunafit, Nugroho. 2006)

Konsep dasar dari sebuah sistem informasi manajemen adalah :

1. Konsep Informasi

Jurnal Ilmiah “Technologia"
Informasi menambah suatu penyajian, yaitu sehubungan dengan waktu dan mutu informasi.

2. Manusia sebagai pengolah data

Kemampuan sebagai pengolah informasi menentukan sebuah keterbatasan dalam sistem informasi dan mengesankan dasar-dasar rancangan mereka.

3. Konsep Sistem

Karena sistem informasi manajemen merupakan sebuah sistem, maka konsep sistem dipandang perlu untuk memahami dan merancang pada pengembangan sistem informasi.

4. Konsep Informasi dan Manajemen

Sistem informasi berada dalam sebuah organisasi dan dirancang untuk mendukung fungsi manajemen.

5. Rancangan sistem informasi manajemen

Rancangan sistem informasi manajemen, bukan hanya mencerminkan rancangan rasional terhadap organisasi, tetapi teori perilaku pengambilan keputusan dalam organisasi.

6. Nilai Informasi

Informasi mengubah keputusan, perubahan dalam nilai akan menentukan informasi.

D. Bahasa Pemprograman PHP

Pemrograman PHP menurut Nugroho (2006b:61) "PHP atau singkatan dari Personal Home Page merupakan bahasa skrip yang tertanam dalam HTML untuk dieksekusi bersifat server side". PHP termasuk dalam open source product, sehingga source code PHP dapat diubah dan didistribusikan secara bebas. Versi terbaru PHP dapat diunduh secara gratis melalui situs resmi PHP : http://www.php.net.

PHP juga dapat berjalan pada berbagai web server seperti IIS (Internet Information Server), PWS (Personal Web Server), Apache, Xitami. PHP juga mampu berjalan di banyak sistem operasi yang beredar saat ini, diantaranya : Sistem Operasi Microsoft 
Windows (semua versi), Linux, Mac Os, Solaris. PHP dapat dibangun sebagai modul web server Apache dan sebagai binary yang dapat berjalan sebagai CGI (Common Gateway Interface). PHP dapat mengirim HTTP header, dapat mengatur cookies, mengatur authentication dan redirect user.

Salah satu keunggulan yang dimiliki PHP adalah kemampuannya untuk melakukan koneksi ke berbagai macam software sistem manajemen basis data atau Database Management Sistem (DBMS), sehingga dapat menciptakan suatu halaman web dinamis. PHP mempunyai koneksitas yang baik dengan beberapa DBMS seperti Oracle, Sybase, mSQL, MySQL, Microsoft SQL Server, Solid, PostgreSQL, Adabas, FilePro, Velocis, dBase, Unix dbm, dan tidak terkecuali semua database berinterface ODBC.

Hampir seluruh aplikasi berbasis web dapat dibuat dengan PHP. Namun kekuatan utama adalah konektivitas basis data dengan web. Dengan kemampuan ini kita akan mempunyai suatu sistem basis data yang dapat diakses.

\section{E. PHP}

Menurut Arief (2011d:43) "PHP (Perl Hypertext Preprocessor) adalah bahasa server-side-scripting yang menyatu dengan HTML untuk membuat halaman web yang dinamis". Dengan menggunakan program PHP, sebuah website akan lebih interaktif dan dinamis.

Adapun kelebihan-kelebihan dari PHP yaitu:

1. PHP merupakan sebuah bahasa script yang tidak melakukan sebuah kompilasi dalam penggunaannya. Tidak seperti halnya bahasa pemrograman aplikasi yang lainnya.

2. PHP dapat berjalan pada web server yang dirilis oleh Microsoft, seperti IIS atau PWS juga pada apache yang bersifat open source.

3. Karena sifatnya yang open source, maka perubahan dan perkembangan interpreter pada PHP lebih cepat dan mudah, karena banyak milis-milis dan developer yang siap membantu pengembanganya.

4. Jika dilihat dari segi pemahaman, PHP memiliki referensi yang begitu banyak sehingga sangat mudah untuk dipahami.

5. PHP dapat berjalan pada 3 operating sistem, yaitu: Linux, unux, dan windows, dan juga dapat dijalankan secara runtime pada suatu console.

\section{F. Xampp}

XAMPP adalah sebuah software web server apache yang didalamnya sudah tersedia database server mysql dan support php programming. XAMPP merupakan software yang mudah digunakan, gratis dan mendukung instalasi di Linux dan Windows. Keuntungan lainnya adalah cuma menginstal satu kali sudah tersedia Apache Web Server, MySQL Database Server, PHP Support (PHP 4 dan PHP 5) dan beberapa module lainnya. Hanya bedanya kalau yang versi untuk Windows sudah dalam bentuk instalasi grafis dan yang Linux dalam bentuk file terkompresi. Kelebihan lain yang berbeda dari versi untuk Windows adalah memiliki fitur untuk mengaktifkan sebuah server secara grafis, sedangkan Linux masih berupa perintah-perintah di dalam console. Oleh karena itu yang versi untuk Linux sulit untuk dioperasikan. Dulu XAMPP untuk Linux dinamakan LAMPP, sekarang diganti namanya menjadi XAMPP FOR LINUX.

XAMPP merupakan tool yang menyediakan paket perangkat lunak ke dalam satu buah paket. Dengan menginstal XAMPP maka tidak perlu lagi melakukan instalasi dan konfigurasi web server Apache, PHP dan MySQL secara manual. XAMPP akan menginstalasi dan mengkonfigurasikannya secara otomatis untuk anda atau auto konfigurasi.

G. Database MySQL

Menurut (Kadir, Mudah mempelajari Database MySQL, 2009) MySQL adalah sebuah perangkat lunak system manajemen 
basis data SQL (DBMS) yang multithread, dan multi-user. MySQL adalah implementasi dari system manajemen basis data relasional (RDBMS). MySQL dibuah oleh TcX dan telah dipercaya mengelola system dengan 40 buah database berisi 10.000 tabel dan 500 di antaranya memiliki 7 juta baris. MySQL AB merupakan perusahaan komersial Swedia yang mensponsori dan yang memiliki MySQL. Pendiri MySQL AB adalah dua orang Swedia yang bernama David Axmark, Allan Larsson dan satu orang Finlandia bernama Michael "Monty".

Setiap pengguna MySQL dapat menggunakannya secara bebas yang didistribusikan gratis dibawah lisensi GPL (General Public License) namun tidak boleh menjadikan produk turunan yang bersifat komersial. Pada saat ini MySQL merupakan database server yang sangat terkenal di dunia, semua itu tak lain karena bahasa dasar yang digunakan untuk mengakses database yaitu SQL. SQL (Structured Query Language) pertama kali diterapkan pada sebuah proyek riset pada laboratorium riset San Jose, IBM yang bernama system R. Kemudian SQL juga dikembangan oleh Oracle, Informix dan Sybase, dengan menggunakan SQL, proses pengaksesan database lebih userfriendly dibandingan dengan yang lain, misalnya Base atau Clipper karena mereka masih menggunakan perintah-perintah pemrograman murni.

\section{H. Sublime Text}

Sublim text adalah aplikasi editor untuk kode dan teks yang dapat berjalan di berbagai platform opertaing system dengan menggunakan teknologi Phyton API. Terciptanya aplikasi iini terinspirasi dari aplikasi Vim, aplikasi ini sangatlah fleksibel dan powerfull. Fungsionalitas dari aplikasi ini dapat dikembangkan dengan menggunakan sublime packages. Sublime text bukanlah aplikasi open source dan juga aplikasi yang dapat digunakan dan didapatkan secara gratis, akan tetapi beberapa fitur pengembangan Jurnal Ilmiah "Technologia" fungsionalitas (packages) dari aplikasi ini merupakan hasil dari temuan dan mendapat dukungan penuh dari komunitas serta memiliki lisensi aplikasi gratis. Sublime text mendukung berbagai bahasa pemrograman dan mampu menyajikan fitur syntax highlight hampir di semua bahasa pemrograman yang didukung ataupun dikembangkan oleh komunitas seperti; C, $\mathrm{C}++, \mathrm{C \#}, \mathrm{CSS}$, D, Dylan, Erlang, HTML, Groovy, Haskell, Java, Javascript, LaTex, Lisp, Lua, Markdown, MATLAB, Ocaml, Perl, PHP, Python, R, Ruby, SQL, TCL, Textile dan XML. Biasanya bagi bahasa pemrograman yang didukung ataupun belum terdukung secara default dapat lebih dimaksimalkan atau didukung dengan menggunakan add ons yang bisa didownload sesuai kebutuhan user. (Lambokhasi, 2006) Berikut beberapa fitur yang diunggulkan dari aplikasi sublime text: 1. Goto Anything

Fitur yang sangat membantu dalam membuka file ataupun menjelajahi isi dari file hanya dengan beberapa keystrokes.

2. Multiple Selection

Fitur ini memungkinkan user untuk mengubah secara interaktif banyak baris sekaligus, mengubah nama variabel dengan mudah, dan memanipulasi file lebih cepat dari sebelumnya.

3. Command Pallete

Dengan hanya beberapa keystrokes, user dapat dengan cepat mencari fungsi yang diinginkan, tanpa harus menavigasi melalui menu.

2. Distraction Free Mode

Bila user memerlukan fokus penuh pada aplikasi ini, fitur ini dapat membantu user dengan memberikan tampilan layar penuh.

3. Split Editing

Dapatkan hasil yang maksimal dari monitor layar lebar dengan dukungan editing perpecahan. Mengedit sisi file dengan sisi, atau mengedit dua lokasi di satu file. Anda dapat mengedit dengan banyak baris dan kolom yang user inginkan.

4. Instant Project Switch 
Menangkap semua file yang dimasukkan ke dalam project pada aplikasi ini. Terintegritas dengan Goto Anything untuk menjelajahi semua file yang ada ataupun untuk beralih ke file dalam project lainnya dengan cepat.

5. Plugin API

Dilengkapi dengan plugin API berbasi Phyton sehingga membuat aplikasi ini sangat tangguh.

6. Customize Anything

Aplikasi ini memberikan user fleksibilitas dalam hal pengaturan fungsional dalam aplikasi ini.

7. Cross Platform

Aplikasi ini dapat berjalan hampir disemua operating system modern seperti Windows, OS X, dan Linux based operating system.

\section{ANALISIS DAN PERANCANGAN} SISTEM

A. Use Case Diagram

Data Use Case Diagram Aplikasi Pengelolaan Panti Sosial Bina Remaja (PSBR) "Budi Satria" adalah sebagai berikut :

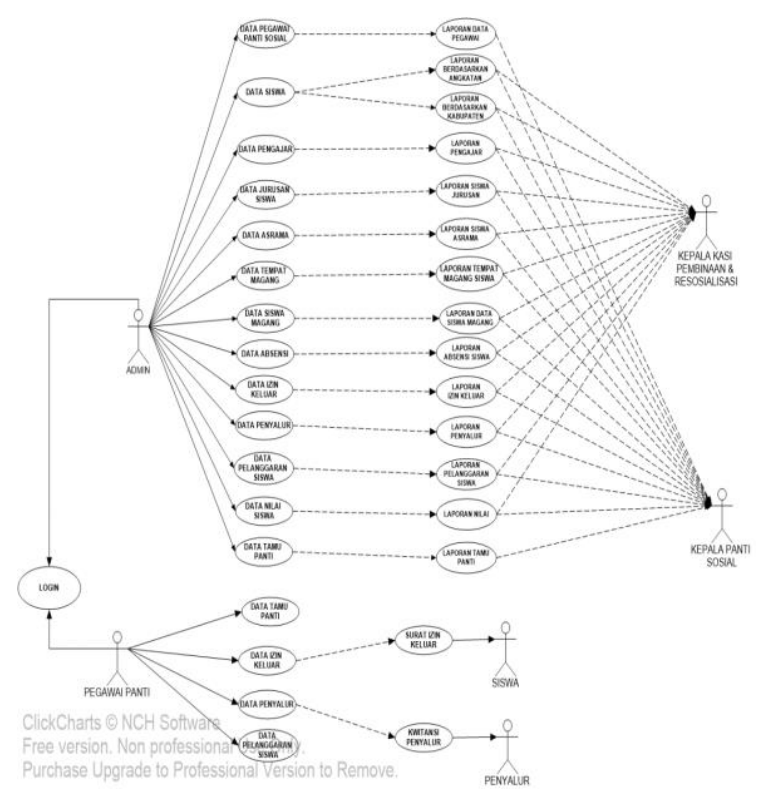

Keterangan :

1. Admin sangat berperan penting dan terlibat langsung pada semua peroses yang terjadi, pada proses ini admin dapat melakukan penginputan, pengeditan, dan

Jurnal Ilmiah “Technologia" penghapusan data-data dalam aplikasi pengelolaan PSBR "Budi Satria", dan dapat melakukan pembuatan laporan yang akan di serahkan kepada kepala kasi pembinaan \& reseolisasi dan kepada kepala panti.

2. Pegawai panti hanya berperan di dalam penginputan data tamu, penginputan izin keluar siswa beserta surat izin, penginputan penyalur beserta kwitansi untuk penyalur, dan penginputan pelanggaran siswa.

\section{B. Class Diagram}

Data Class Diagram Aplikasi

Pengelolaan Panti Sosial Bina Remaja (PSBR) "Budi Satria" adalah sebagai berikut :

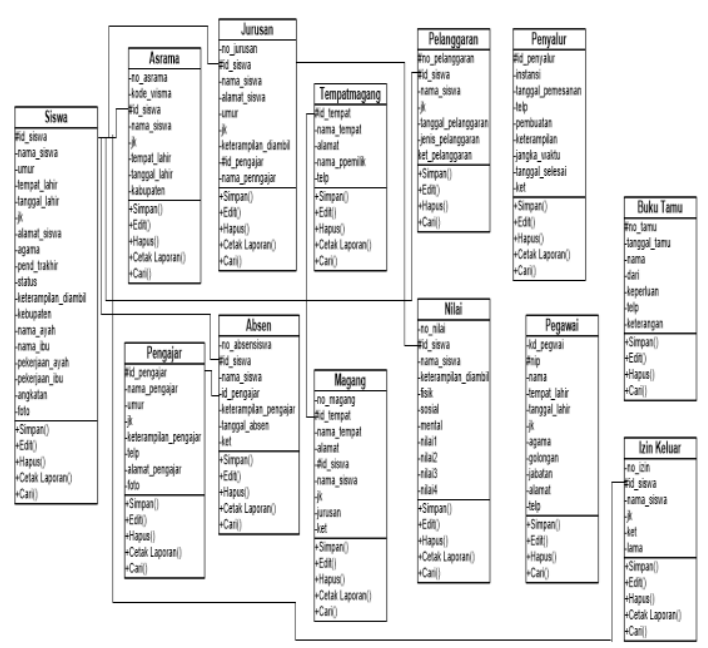

Keterangan :

Class Diagram adalah sebuah class yang menggambarkan struktur dan penjelasan hubungan antar class dalam sebuah sistem yang sedang perancangan pengelolaan PSBR "Budi Satria" yang saling terhubung satu sama lain dan bagaimana caranya agar mereka saling berkolaborasi untuk mencapai sebuah tujuan.

\section{HASIL DAN PEMBAHASAN}

A. Halaman Menu Utama 


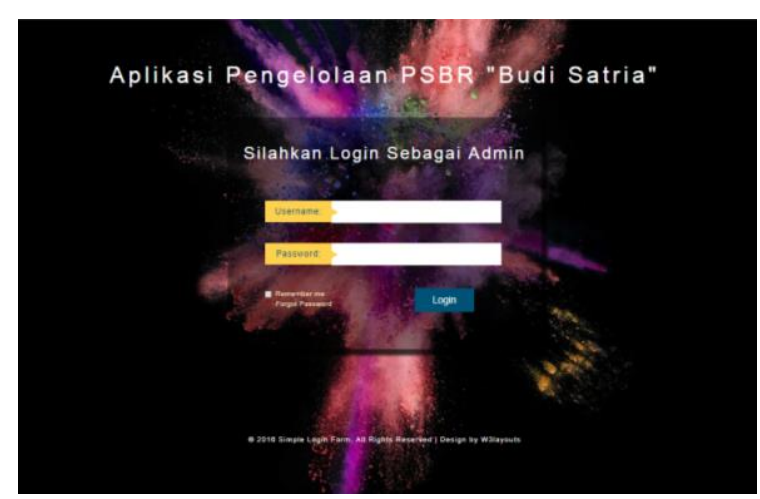

Pada Halaman ini Admin Memasukkan username dan password yang sudah di daftarkan sebelumnya dan kemudian klik button login, sehingga berhasil masuk kedalam sistem untuk akses login terdapat 2 admin.

\section{B. Tampilan Halaman Menu Utama Admin 1}

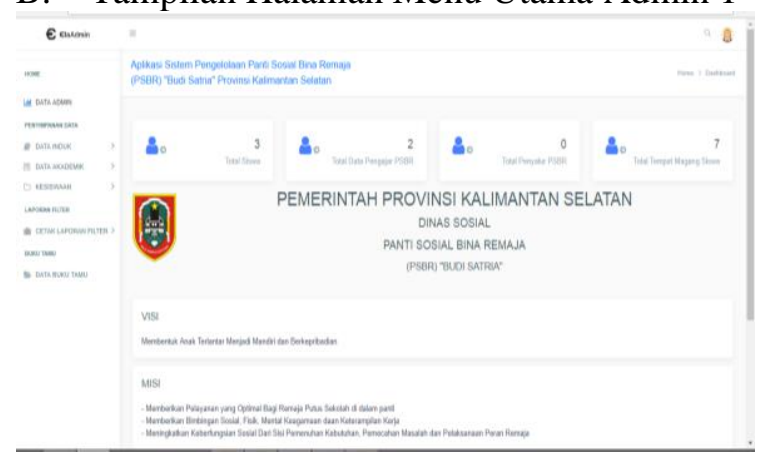

Tampilan Halaman Utama admin utama, Pada halaman ini admin dapat mengola website dengan melilih menu yang disediakan pada sisi sebelah kiri dimana pada menu tersebut disediakan, akses untuk menampilkan, menambah, mengedit dan menghapus data, data yang dikelola meliputi Data Induk, Data Akademik, Kesiswaan, Cetak Laporan Filter, dan Buku Tamu.

C. Menu Utama Admin 2

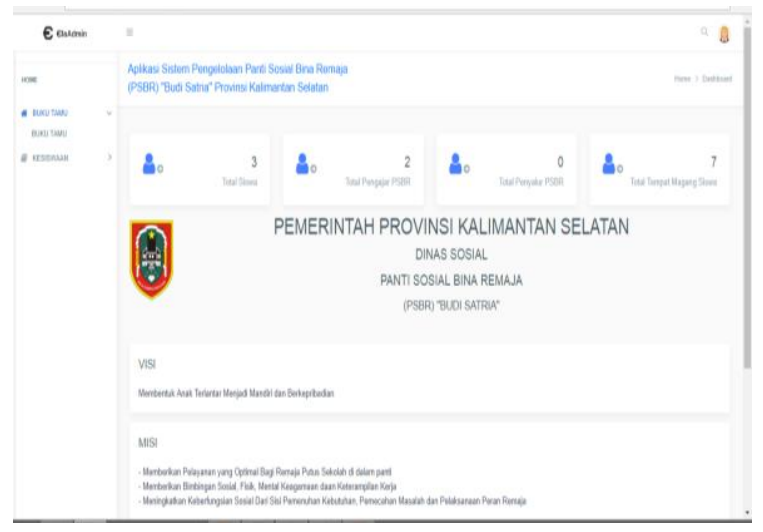

D. Inputan Data Siswa

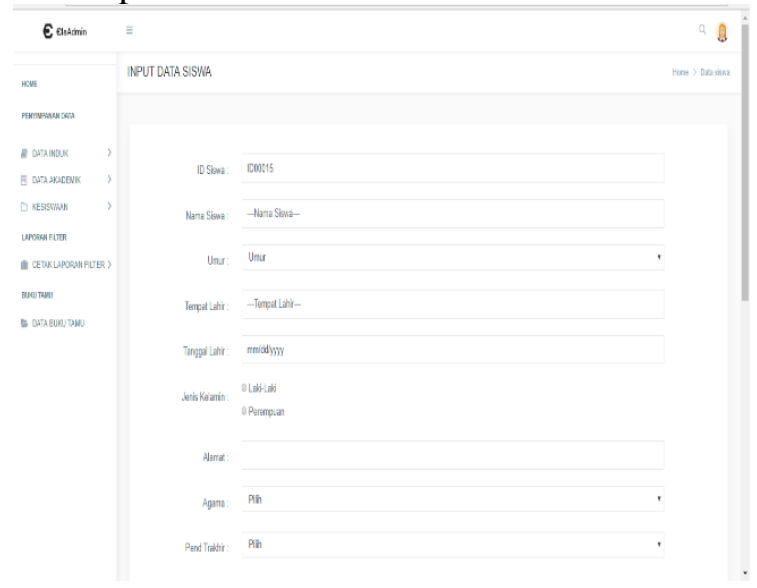

Menampilkan form simpan data siswa dengan inputan seperti id siswa, nama siswa, umur, tempat lahir, tanggal lahir, jenis kelamin, alamat, agama, pendidikan trakhir, status, nama orang tua, foto siswa, dan lain-lainnya seperti pada gambar diatas dengan tombol aksi simpan untuk menyimpan data ke database, batal untuk mengosongkan form inputan, dan kembali untuk kembali ke halaman sebelumnya. Apabila ada data yang kosong maka data tidak akan tersimpan ke database dan akan menampilkan peringatan berupa validasi bahwa ada data yang masih kosong atau data yang masih belum diisi.

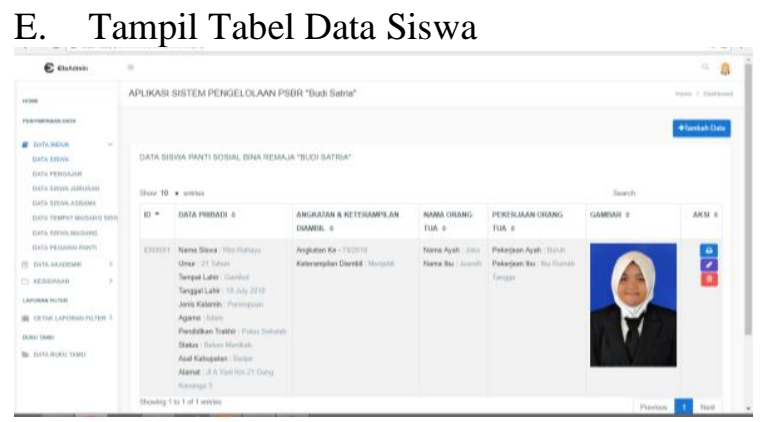


Setelah menginput data dan tersimpan maka akan di tampilkan di tabel data siswa yang terdiri dari id siswa, nama siswa dan lainlainnya seperti gambar yang ada diatas dengan tombol aksi print untuk cetak identitas siswa, tombol edit untuk mengedit data apabila terjadi kesalahan dalam simpan data dan tombol hapus data untuk menghapus data yang salah.

\section{F. Inputan Data Pengajar}

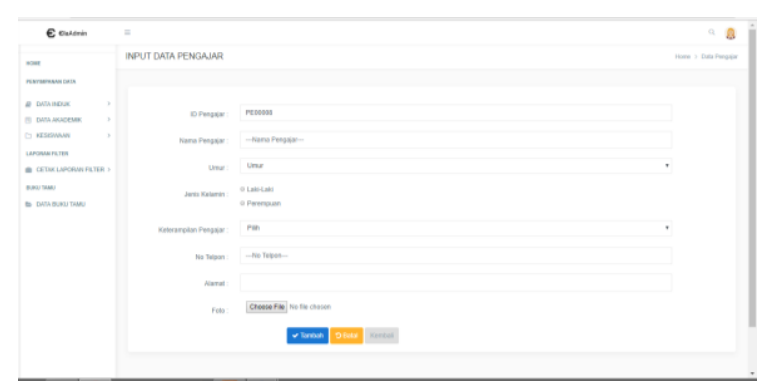

Menampilkan form simpan data pengajar dengan inputan seperti id pengajar, nama pengajar, umur, jenis kelamin, keterampilan pengajar, nomer telpon, alamat, dan foto, seperti pada gambar diatas dengan tombol aksi simpan untuk menyimpan data ke database, batal untuk mengosongkan form inputan, dan kembali untuk kembali ke halaman sebelumnya. Apabila ada data yang kosong maka data tidak akan tersimpan ke database dan akan menampilkan peringatan berupa validasi bahwa ada data yang masih kosong atau data yang masih belum diisi.

\section{G. Tampilan Tabel Data Pengajar}

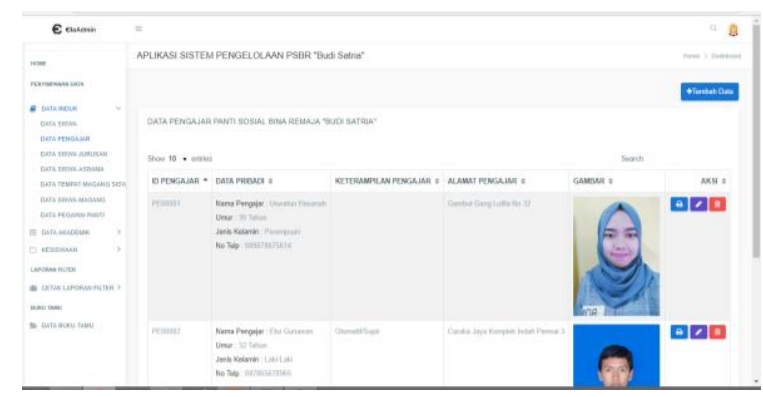

Setelah menginput data dan data tersimpan maka akan di tampilkan di tabel data pengajar yang terdiri dari id pengajar, nama pengajar, umur, jenis kelamin dan Jurnal Ilmiah “Technologia” lain-lainnya seperti gambar yang ada di atas dengan tombol aksi print untuk cetak identitas pengajar, tombol edit untuk mengedit data apabila terjadi kesalahan dalam simpan data dan tombol hapus data untuk menghapus data yang salah.

H. Laporan Data Siswa Berdasarkan Angkatan

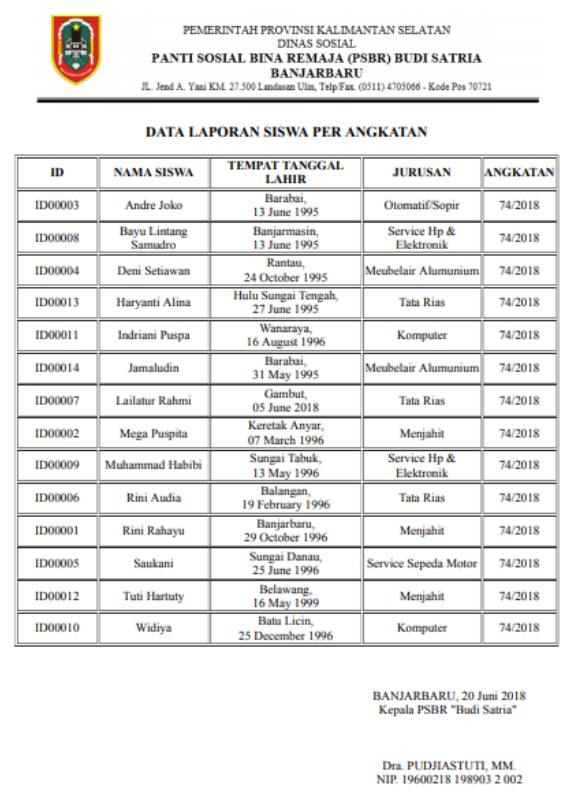

Halaman laporan data siswa per angkatan ini filter dari data siswa, berfungsi untuk melaporkan data siswa per angkatan. Halaman ini merupakan submenu dari menu cetak laporan filter.

\section{KESIMPULAN}

Pembangunan Aplikasi Sistem Pengelolaan Panti Sosial Bina Remaja "Budi Satria" Banjarbaru merupakan pengembangan dari sistem yang sedang berjalan. Berbagai permasalahan yang muncul telah diupayakan untuk dapat ditangani dengan sistem baru yang diusulkan ini. Adapun kesimpulan yang dapat diambil dari pembangunan aplikasi pengelolaan ini antara lain :

1. Aplikasi pengelolaan PSBR "Budi Satria" yang dibuat dapat membantu dalam pengolahan data siswa, data pengajar ,dan data akademik siswa lebih efektif dan efisien sehingga dapat meningkatkan produktivitas kinerja. 
2. Aplikasi pengelolaan PSBR "Budi Satria" yang dibuat sudah melakukan proses pencarian data siswa, pengajar, dan akademik dengan cepat karena data sudah dapat tersimpan kedalam database yang terintegrasi

3. Aplikasi pengelolaan yang dibuat sebagai media pencatatan akademik di Panti Sosial Bina Remaja "Budi Satria" Banjarbaru yang dapat memberikan informasi akademik dan kesiswaan panti.

\section{REFERENSI}

Andri, Kristanto. 2003. Perancangan Sistem Informasi dan Aplikasi. Gava Media :Jakarta.

Jazuli, R. (2017, 12 oktober). Pengertian UML(Unified Modelling Languange) Dan Macam-Macam Diagramnya . Retrieved from Selamat Belajar: https://www.itseeboy.com/2017/10/pengertia n-umlunified-modelling.html

Kadir, A. (2002). Pengenalan Sistem Informasi. Yogyakarta: Andi.

Kadir, A. (2009). Mudah mempelajari Database MySQL. Yogyakarta: Mediakom.

Kadir, A., \& Syamsiar, S. (2011). Panduan Menyusun Laporan Tugas Akhir, Skripsi, dan Tesis menggunakan Microsoft Word. Yogyakarta: Mediakom.

Kristanto, H. (1994). Konsep Dan Perancangan Database. Yogyakata: Andi Offset.

MySQL, M. M. (2009). Abdul Kadir. Yogyakarta: Mediakom.

nanda, a. (2012, 19 november). Pengertian PHP (Perl Hypertext Preprocessor) . Retrieved from ehnanda: http://ehnanda.blogspot.co.id/2015/01/pengert ian-php-perl-hypertext.html

Parno, S. (2010). langkah-Langkah Dalam Pembuatan Data Flow Diagram. Surabaya: Mediacom.

Rahman, A. (2012). Pengenalan PHP. Bandung: Jurnal.

ritongga, p. (2015, 27 maret). Pengertian Bahasa pemrograman PHP menurut para pakar. Retrieved from bangpahmi.com: http://www.bangpahmi.com/2015/03/pengerti an-bahasa-pemrograman-php.html Jurnal Ilmiah "Technologia"
Supriyanto. (2005). Pengantar Teknologi Informasi. Jakarta: Salemba Empat.

Saiful, A. (2012, 12 desember). Pengenalan simbol use case diagram pada $U M L$. Retrieved from oom azhar: http://azharkesatriatiwolawolawol.blogspot.c om/2014/06/pengenalan-simbol-use-casediagram-pada.html

Tata Sutabri. 2004. Analisa Sistem Informasi. Andi : Yogyakarta

Wibisono, D. (2013). Panduan Menyusun Skripsi, Tesis, dan DIsertasi. Yogyakarta: CV. ANDI OFFSET. 